\title{
DIAGNÓSTICO AMBIENTAL DOS IMPACTOS DA PROLIFERAÇÃO DE VEGETAÇÃO MACRÓFITA NO LAGO BOLONHA NA CIDADE DE BELÉM-PA
}

Ana Lívia Cantuária Andrade - al.cantuaria@gmail.com

Universidade do Estado do Pará

Paulo Amador Tavares - atavares.paulo@gmail.com

Universidade do Estado do Pará

Yago Rodrigues Santos -yagorsantos2@gmail.com

Instituto Nacional de Pesquisas da Amazônia

Lúcio Davi Moraes Brabo - anklucio@gmail.com

Egresso da Universidade do Estado do Pará

Hebe Morganne Campos Ribeiro - hebemcr@gmail.com

Universidade do Estado do Pará

Norma Ely Santos Beltrão - normaelybeltrao@ gmail.com

Universidade do Estado do Pará 


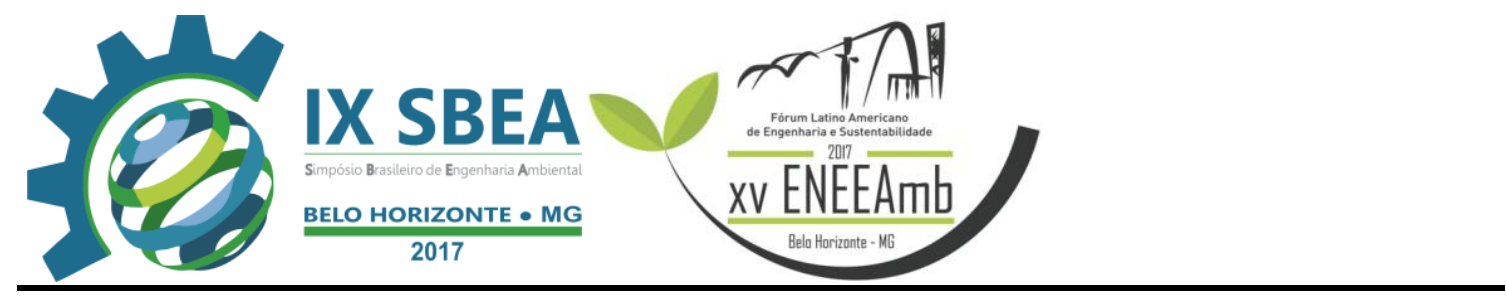

\section{RESUMO}

O objetivo geral deste artigo foi realizar um diagnóstico ambiental da proliferação de macrófitas no sistema hidrográfico do Utinga no município de Belém/PA, além de avaliar a qualidade dos fatores impactantes na área de estudo e identificar as principais medidas a serem tomadas para que estes fatores sejam solucionados. Para o diagnóstico ambiental, foi realizada revisão de literatura relacionada à área de estudo para levantamento dos principais impactos na área, e para elencar os aspectos ambientais, aplicou-se um "check-list" preenchido através de observações por meio de dados secundários. A maioria dos fatores impactantes tem danos negativos sobre o lago. Sendo os efeitos dos danos, em geral, de longa duração e permanentes ou periódica no caso de danos estruturais as sistema de abastecimento. Uma alternativa a ser utilizada é a direcionamento da vegetação retirada ou cortada do lago para a produção de biogás, o qual poderá ser usado como fonte de energia, dando um direcionamento sustentável ao caso.

Palavras-chave: macrófitas, fatores impactantes, diagnóstico.

\section{INTRODUÇÃO/OBJETIVO}

O termo "macrófitas aquáticas" foi introduzido pela primeira vez por Cook (1974) que o definiu como todas as plantas cujas partes fotossinteticamente ativas estão, permanentemente ou por alguns meses, submersas ou flutuantes em água e sejam visíveis a olho nu.

A presença deste tipo de vegetação aquática em reservatórios é bastante comum. Segundo Junk e Mello (1990), sua proliferação é um dos fenômenos biológicos mais alarmantes em represas tropicais, pois possui em especial os principais fatores que levam à sua superpopulação além de sua alta capacidade reprodutiva: alto nível de nutrientes; condições climáticas favoráveis; falta de espécies competidoras; e a falta de animais herbívoros, pragas e doenças. Nessas condições ótimas, determinadas espécies podem se tornar daninhas, prejudicando os usos múltiplos dos ecossistemas aquáticos (CAMARGO et al., 2003).

Na cidade de Belém, situação análoga é encontrada, uma vez que os principais mananciais de abastecimento da cidade estão localizados em zonas de pressão, onde a 


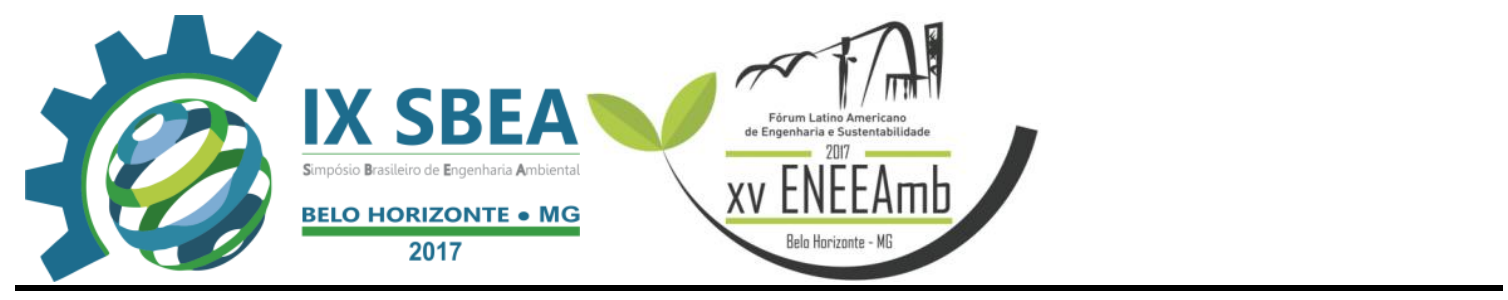

expansão da quantidade de macrófitas nos lagos é rápida e visível para qualquer indivíduo (MENEZES et al., 2013). A busca de soluções ambientalmente corretas para esta área requer diversos estudos, uma vez que podem significar um impacto ambiental, social e econômico para a região (GUTIERREZ et al., 2017; MACEDO et al., 2013).

Tendo em vista esta problemática, objetivo geral deste artigo é realizar o diagnóstico ambiental da proliferação de macrófitas no sistema hidrográfico do Utinga no município de Belém/PA. Têm-se por objetivos específicos avaliar a qualidade dos fatores impactantes na área de estudo e identificar as principais medidas a serem tomadas para que estes fatores sejam solucionados.

\section{METODOLOGIA}

\section{1 Área de estudo}

O lago Bolonha está localizado dentro do Parque Estadual do Utinga, Belém-PA, como é apresentado na Figura 1. Esta região possui um clima caracterizado como Am (clima tropical de monção) e Af (clima tropical úmido ou equatorial), de acordo com a classificação Köppen-Geiger. A precipitação média da área é de 3.287 milímetros por ano, a temperatura média anual é de 33 graus Celsius, a média da umidade relativa do ar é de $84 \%$ e velocidade média do ar é de 7 quilômetros por hora, predominantemente no sentido Nordeste (NE) e Leste (E) (PARÁ, 2013). 


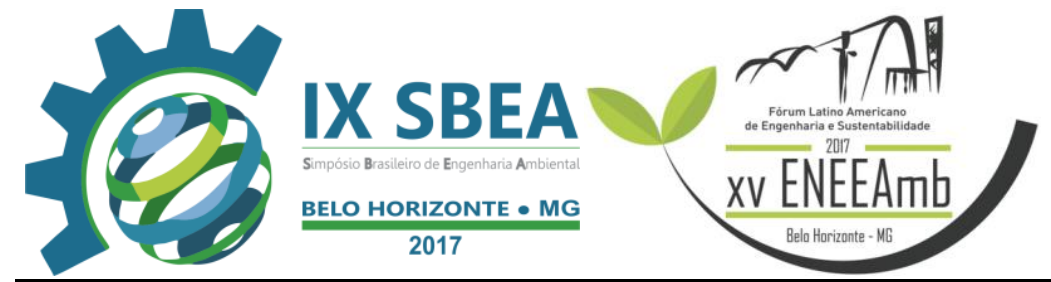

Figura 1 - Área de estudo mostrando o Parque Estadual do Utinga, localizado entre os municípios de Belém e Ananindeua, e os lagos Bolonha e Água Preta dentro da área deste parque.

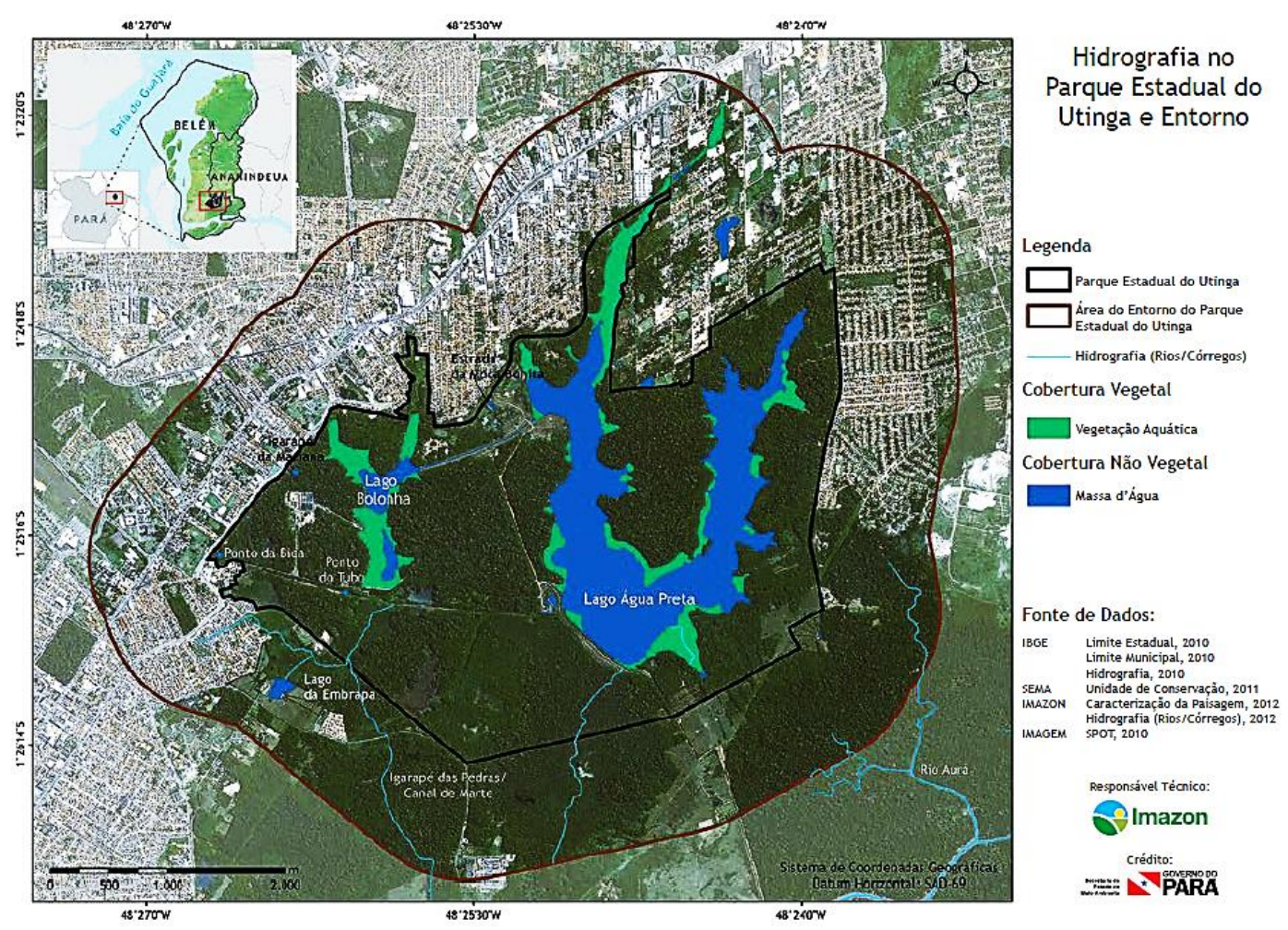

Fonte: PARÁ, 2013.

\subsection{Análise e coleta de dados}

Para o diagnóstico ambiental, foi realizada revisão de literatura relacionada à área de estudo para levantamento dos principais impactos na área, para elencar os aspectos ambientais observados por meio de dados secundários, foi aplicado um "checklist" conforme o método adaptado e proposto por Rodrigues et al. (2015), onde foram identificados os impactos e depois elaborada sua classificação qualitativa e quantitativa, utilizando critérios de acordo com o quadro 1. Para análise das ações impactantes foi utilizada como referência a Resolução do CONAMA nº 001/86, com os parâmetros descritos pelo levantamento de literatura a respeito dos impactos normalmente gerados. 


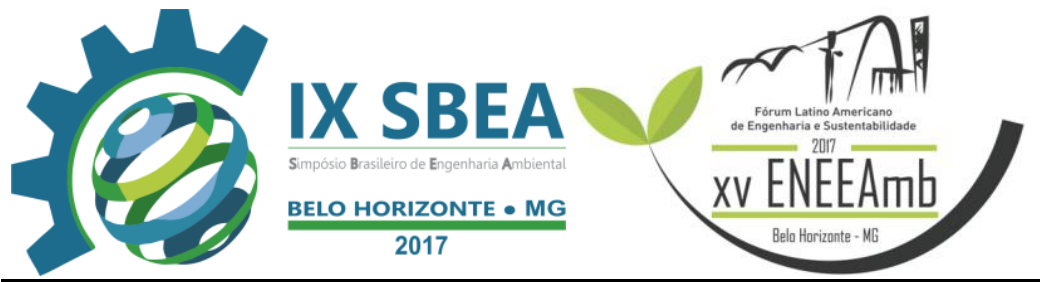

Quadro 1 - Caracterização dos impactos ambientais conforme resolução do CONAMA nº 001/86

\begin{tabular}{|c|c|c|c|}
\hline Aspecto & PA & $\mathbf{S}$ & Descrição \\
\hline Efeito & $\begin{array}{l}\text { Negativo } \\
\text { Positivo }\end{array}$ & $\mathrm{N}$ & $\begin{array}{l}\text { - Dano à qualidade de um fator ou parâmetro } \\
\text { ambiental. } \\
\text { - Melhoria de um fator ou parâmetro ambiental. }\end{array}$ \\
\hline Ordem & $\begin{array}{l}\text { Nulo } \\
\text { Direto } \\
\text { Indireto }\end{array}$ & $\begin{array}{l}0 \\
\mathrm{D} \\
\mathrm{I}\end{array}$ & $\begin{array}{l}\text { - Fator cujos efeitos inexistem. } \\
\text { - Simples relação de causa e efeito. } \\
\text { - Ação secundária, ou quando é parte de uma } \\
\text { cadeia de reações. }\end{array}$ \\
\hline Tempo & $\begin{array}{l}\text { Cíclico } \\
\text { Curto } \\
\text { Médio } \\
\text { Longo }\end{array}$ & $\begin{array}{l}\mathrm{Ci} \\
\mathrm{C} \\
\mathrm{M} \\
\mathrm{L}\end{array}$ & $\begin{array}{l}\text { - Efeitos se fazem sentir de forma cíclica ou } \\
\text { periódica. } \\
\text { - A ação permanece num curto espaço de Tempo. } \\
\text { - A ação pode ser cessada após um tempo. } \\
\text { - O efeito permanece após muito tempo após ter-se } \\
\text { dado à ação. }\end{array}$ \\
\hline Dinâmica & $\begin{array}{l}\text { Estratégico } \\
\text { Temporário } \\
\text { Permanente }\end{array}$ & $\begin{array}{l}\mathrm{E} \\
\mathrm{T} \\
\mathrm{P}\end{array}$ & $\begin{array}{l}\text { - Efeito assume reflexo estadual ou nacional. } \\
\text { - O efeito do impacto permanece por um } \\
\text { determinado tempo, após o qual depois } \\
\text { desaparece. } \\
\text { - Os efeitos não cessam de se manifestar num } \\
\text { horizonte temporal conhecido. }\end{array}$ \\
\hline Plástica & $\begin{array}{l}\text { Reversível } \\
\text { Irreversível }\end{array}$ & $\begin{array}{l}\mathrm{R} \\
\mathrm{IR}\end{array}$ & $\begin{array}{l}\text { - O local pode voltar a ter a paisagem original. } \\
\text { - Após a ação impactante, mesmo com medidas } \\
\text { mitigadoras, o local não volta a ter a paisagem } \\
\text { original. }\end{array}$ \\
\hline Magnitude & $\begin{array}{l}\text { Pequena } \\
\text { Média } \\
\text { Grande }\end{array}$ & $\begin{array}{r}1-3 \\
4-6 \\
7-10\end{array}$ & $\begin{array}{l}\text { - O meio permanece inalterado. } \\
\text { - O meio apresenta uma leve alteração quanto à sua } \\
\text { paisagem, porém de forma inexpressiva. } \\
\text { - A ação altera toda a paisagem. }\end{array}$ \\
\hline $\begin{array}{l}\text { Espaço/ } \\
\text { Escala }\end{array}$ & $\begin{array}{c}\text { Local } \\
\text { Regional }\end{array}$ & $\begin{array}{l}\text { Lo } \\
\operatorname{Re}\end{array}$ & $\begin{array}{l}\text { - Afeta apenas a área local do empreendimento. } \\
\text { - O efeito extrapola a área de implantação do } \\
\text { empreendimento. }\end{array}$ \\
\hline Frequência & $\begin{array}{l}\text { Baixa } \\
\text { Média } \\
\text { Alta }\end{array}$ & $\begin{array}{l}1 \\
2 \\
3\end{array}$ & $\begin{array}{l}\text { - Sem danos ou com danos mínimos ao meio } \\
\text { ambiente. } \\
\text { - Leve alteração quanto à sua paisagem, porém de } \\
\text { forma inexpressiva. } \\
\text { - A ação altera toda a paisagem }\end{array}$ \\
\hline Significância & $\begin{array}{c}\text { Não } \\
\text { Significativa } \\
\text { Moderada } \\
\text { Significativa }\end{array}$ & $4-6$ & $\begin{array}{l}\text { - Não altera a qualidade de vida do meio ou do } \\
\text { homem. } \\
\text { - A área lesionada pela ação, quando negativa, } \\
\text { pode ser recuperada e quando positiva, apresenta } \\
\text { uma melhoria razoável na qualidade de vida. } \\
\text { - Apresenta uma significativa evolução benéfica ao } \\
\text { meio ambiente, quando positiva, e uma perda na } \\
\text { qualidade de vida quando negativa }\end{array}$ \\
\hline
\end{tabular}

Fonte: BRASIL (1986). 


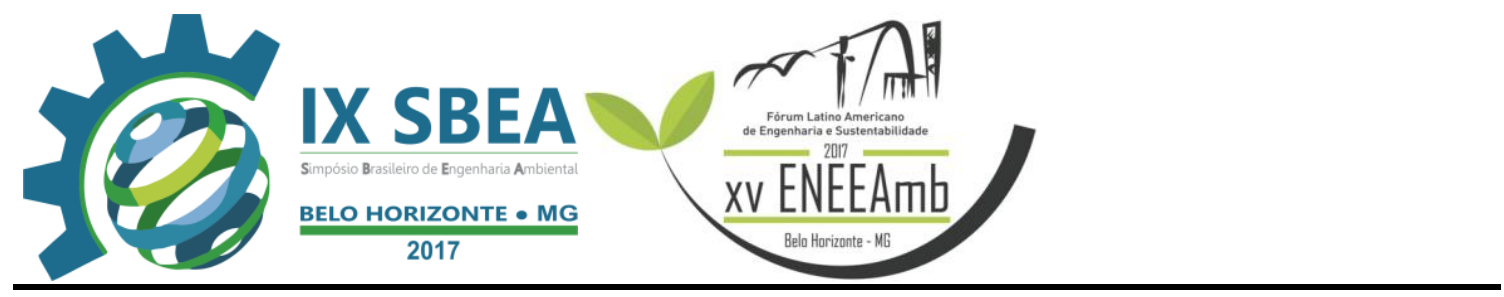

\section{RESULTADOS E DISCUSSÃO}

Dentro desta perspectiva, as principais ações impactantes observadas na área estudo são descritas e analisadas na figura 3: Disposição de maior quantidade de matéria orgânica, absorção de nutrientes, proliferação em partes rasas do lago, obstrução de grades de proteção e turbinas, e a proliferação a partir de nutrientes presentes na água.

Pedralli (2003) afirma que a proliferação de macrófitas possui intensa ligação com a aceleração do processo de eutrofização das águas, pois a elevada produção de biomassa, induz o aumento do déficit de oxigênio, a formação de gases (H2S, CH4, etc.) e a diminuição do $\mathrm{pH}$ da água.

Com a grande concentração de macrófitas, há baixa concentração de nutrientes nas águas, pois estes são absorvidos por essas plantas, que consomem parte do oxigênio da água, gerando baixa concentração deste elemento (CARVALHO et al., 2015).

De acordo com Araújo Junior (2015), o crescimento de macrófitas em áreas mais rasas do lago possui ligação com a taxa de assoreamento já que as grandes massas de matéria orgânica resultantes do crescimento dessas plantas, massas estas que tendem a sedimentar depois de mortas no fundo do lago, contribuem para a redução de profundidade, permitindo a fixação de novas plantas em áreas onde antes não era possível o seu desenvolvimento em virtude da maior altura da lâmina d'água.

Outra ação impactante evidenciada é a obstrução de turbinas e grades de proteção. Bianchini Junior (2003) diz que um dos efeitos causados pela grande proliferação de macrófitas é a interferência na operação dos sistemas geradores de energia das usinas hidrelétricas pela necessidade de remoção periódica de biomassa vegetal acumulada nas grades de proteção, deste modo, o mesmo pode ser dito sistemas de captação de água para abastecimento que também fazem uso deste mesmo tipo de estrutura.

Por fim, as macófitas podem ser utilizadas como indicadores da qualidade da água, uma vez que desempenham importantes funções nos ecossistemas aquáticos participando da ciclagem e estocagem de nutrientes, da formação de detritos orgânicos, do controle da poluição e da eutrofização artificial das águas (POTT; POTT, 2003). 


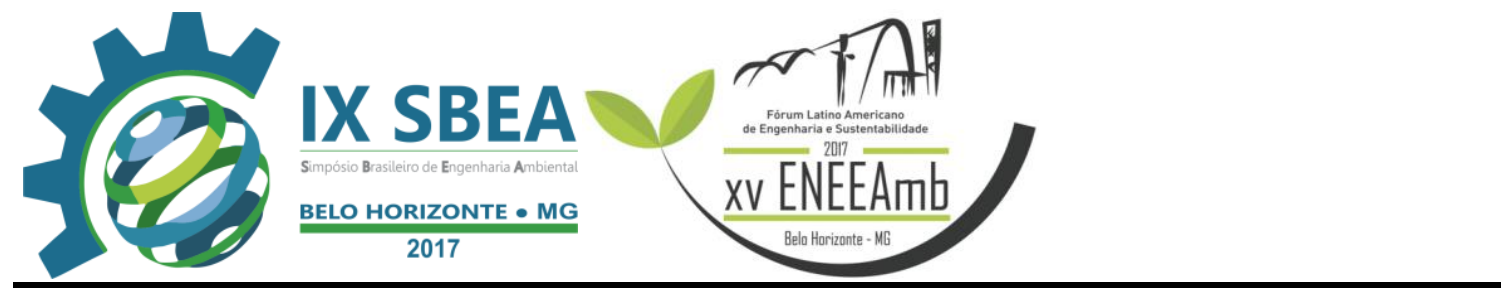

Quadro 2 - Classificação dos impactos observados.

\begin{tabular}{|c|c|c|c|c|c|c|c|c|c|c|}
\hline Ação Impactante & Impacto & 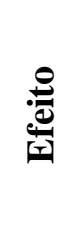 & ప్ & 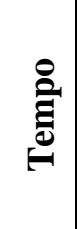 & 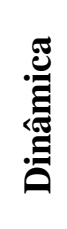 & 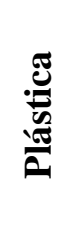 & 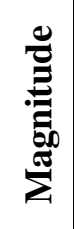 & 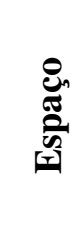 & & 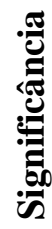 \\
\hline $\begin{array}{c}\text { Dispõe maior } \\
\text { quantidade de } \\
\text { matéria orgânica na } \\
\text { água } \\
\end{array}$ & $\begin{array}{l}\text { Acelera o processo } \\
\text { de Eutrofização }\end{array}$ & $\mathrm{N}$ & I & $\mathrm{L}$ & $P$ & $\mathrm{R}$ & 7 & $\operatorname{Re}$ & 3 & 5 \\
\hline Absorve Nutrientes & $\begin{array}{c}\text { Reduz a quantidade } \\
\text { de oxigênio } \\
\text { presente na água }\end{array}$ & $\mathrm{N}$ & D & $\mathrm{L}$ & $P$ & $\mathrm{R}$ & 3 & $\mathrm{Re}$ & 2 & 5 \\
\hline $\begin{array}{c}\text { Prolifera-se em } \\
\text { partes rasas do lago }\end{array}$ & $\begin{array}{c}\text { Promove } \\
\text { assoreamento }\end{array}$ & $\mathrm{N}$ & $\mathrm{D}$ & $\mathrm{L}$ & $P$ & $\mathrm{R}$ & 8 & Lo & 2 & 5 \\
\hline $\begin{array}{l}\text { Obstrui turbinas e } \\
\text { grades de proteção }\end{array}$ & $\begin{array}{l}\text { Dificulta o } \\
\text { mecanismo de } \\
\text { captação }\end{array}$ & $\mathrm{N}$ & D & CL & $\mathrm{T}$ & $\mathrm{R}$ & 4 & Lo & 1 & 3 \\
\hline $\begin{array}{c}\text { Prolifera-se a partir } \\
\text { de nutrientes } \\
\text { dispostos na água }\end{array}$ & $\begin{array}{l}\text { Torna-se um } \\
\text { bioindicador de } \\
\text { poluição. }\end{array}$ & $P$ & I & $\mathrm{M}$ & $P$ & $\mathrm{R}$ & 8 & Lo & 3 & 3 \\
\hline
\end{tabular}

Fonte: Autores (2017).

\section{CONCLUSÕES/RECOMENDAÇÕES}

Através do diagnóstico feito, foi possível concluir que a maioria dos fatores impactantes tem danos negativos sobre o lago, excetuando-se usar as macrófitas como bioindicador. Os danos são gerados com grau relativamente simples de causa e efeito pela simples presença da vegetação. Sendo os efeitos dos danos, em geral, de longa duração e permanentes ou de maneira cíclica e periódica no caso de danos estruturais as sistema de abastecimento. Entretanto, todos os fatores são reversíveis por medidas de prevenção ou remediativas.

Dentre algumas providências, cabe a simples remoção mecânica ou corte da vegetação em áreas específicas próximas as instalações hidráulicas ou na área total do lago, entretanto, cabe ressaltar que essa é uma medida remediativa, não tendo efeito prolongado, pois a vegetação voltará a crescer. Uma alternativa a ser utilizada é a direcionamento da vegetação para a produção de biogás, o qual poderá ser usado como 


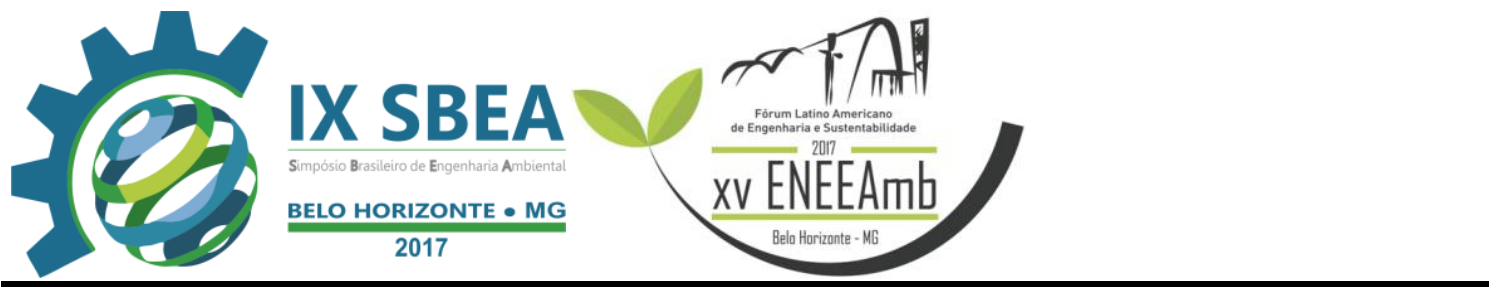

fonte de energia. Sendo que os custos gerados no trabalho de remoção podem ser cobertos com a comercialização desse biogás.

\section{REFERÊNCIAS BIBLIOGRÁFICAS}

ARAÚJO JÚNIOR, A. C. R. Indicadores de Qualidade Ambiental no Lago Bolonha, Parque Estadual do Utinga, Belém-Pará. Boletim Gaúcho de Geografia, v. 42, n. 1, p. 276-299, 2015.

BIANCHINI JÚNIOR, I. Modelos De Crescimento E Decomposição De Macrófitas Aquáticas. In: THOMAZ, S. M.; BINI, L. M. (Org.). Ecologia e Manejo de Macrófitas Aquáticas. Maringá: EDUEM, 2003. p. 85-126.

BRASIL. Conselho Nacional de Meio Ambiente. Resolução no 001, de 23 de janeiro de 1986. Dispõe sobre critérios básicos e diretrizes gerais para o Relatório de Impacto Ambiental - RIMA. Brasília-DF: CONAMA, 1986.

CAMARGO, A. F. M.; PEZZATO, M. M.; HENRY-SILVA, G. G. Fatores Limitantes à Produção Primária de Macrófitas Aquáticas. In: THOMAZ, S. M.; BINI, L. M. (Org.). Ecologia e Manejo de Macrófitas Aquáticas. Maringá: EDUEM, 2003. p. 59-84.

CARVALHO, B. G. P.; TEIXEIRA, L. C. G. M.; PAIVA, R. S.; ARAÚJO JÚNIOR, A. J.S.; CAVAlCANTE, I. C. da S. Avaliação do Desempenho de uma ETA Convencional: Estudo de Caso na ETA Bolonha, Belém-Pará. In: CONGRESSO TÉCNICO CIENTÍFICO DA ENGENHARIA E DA AGRONOMIA CONTECC', 2015, Fortaleza-CE. Anais...Fortaleza-CE: Centro de Eventos do Ceará, 2015.

COOK, C. D. K.; GUT, B. J.; RIX, E. M.; SCHNELLER, J. Water Plants of the World: A Manual for the Identification of the Genera of Freshwater Macrophytes. Springer Science \& Business Media, 1974. 561 p.

GUTIERREZ, C. B. B.; RIBEIRO, H. M. C.; MORALES, G. P.; GUTIERREZ, D. M. G.; SANTOS, L. S. dos; PAUlA, M. T. de. Análise Espaço-Temporal Do Uso E Cobertura Do Solo No Interior Da APA Belém E Correlação Com Os Parâmetros De Água Dos Seus Mananciais. Revista Brasileira de Geografia Física, v. 10, n. 1, p. 521-534, 2017. 


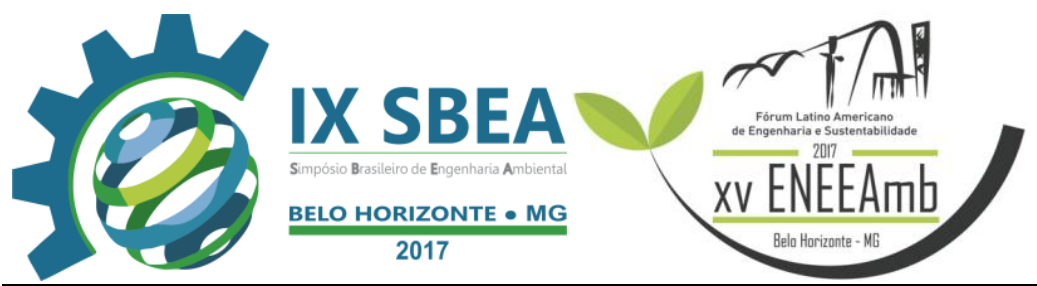

JUNK, W. J.; MELLO, J. A. S. N. de. Impactos Ecológicos das Represas Hidrelétricas na Bacia Amazônica Brasileira. Estudos Avançados, São Paulo, v. 4, n. 8, 1990.

MACEDO, Y. S. L.; TAVARES, P. A.; SANTOS, Y. R.; GONÇALVES, P. V. dos S.; SOUZA, M. J. R. Construção de um Biodigestor para a Produção de Biogás a partir da Fermentação de Macrófitas. In: II SIMPÓSIO DE ESTUDOS E PESQUISA S EM CIÊNCIAS AMBIENTAIS NA AMAZÔNIA, 2013, Belém-PA. Anais... Belém-PA: Centro de Ciências Naturais e Tecnologia, 2013.

MENEZES, L. B. C.; CARVAlhO, E. A. de; NUÑEZ, Y. T.; BRITO, L. B.; SEMBER, N. B. G.; VASCONCELOS, E. O. F. Parques Urbanos de Belém (PA): Situação Atual e Problemáticas Socioambientais. Revista Ciência e Tecnologia, v. 1, n. $1,2013$.

PEDRALLI, G. Macrófitas Aquáticas Como Bioindicadoras Da Qualidade DaÁgua: Alternativas Para Usos Múltiplos De Reservatórios. In: THOMAZ, S. M.; BINI, L. M. (Org.). Ecologia e Manejo de Macrófitas Aquáticas. Maringá: EDUEM, 2003. p. 171189.

POTT, V. J.; POTT, A. Dinâmica da Vegetação Aquática do Pantanal. In: THOMAZ, S. M.; BINI, L. M. (Org.). Ecologia e Manejo de Macrófitas Aquáticas. Maringá: EDUEM, 2003. p. 145-162.

PARÁ. Secretaria de Meio Ambiente e Desenvolvimento Sustentável. Revisão do Plano de Manejo do Parque Estadual do Utinga. Belém: IMAZON, 2013.

RODRIGUES, A.J.; PEREIRA, M.A.; MARTINS, I.C.M.; SOUZA, P.A. Diagnóstico ambiental de um trecho da área de preservação permanente (APP), margens do córrego pouso do meio, em Gurupi-TO. Enciclopédia biosfera, Centro Científico Conhecer Goiânia, v.11 n.21; p. 20153103. 